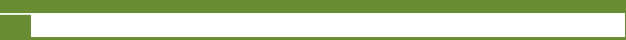

SECCIÓN: Teorías geográficas, geografía de la cultura y la vida cotidiana

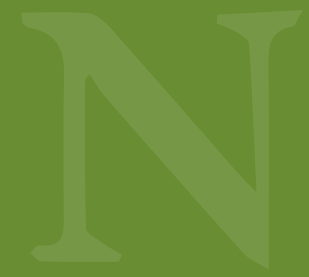

\author{
cultura y la vida cotidian
}
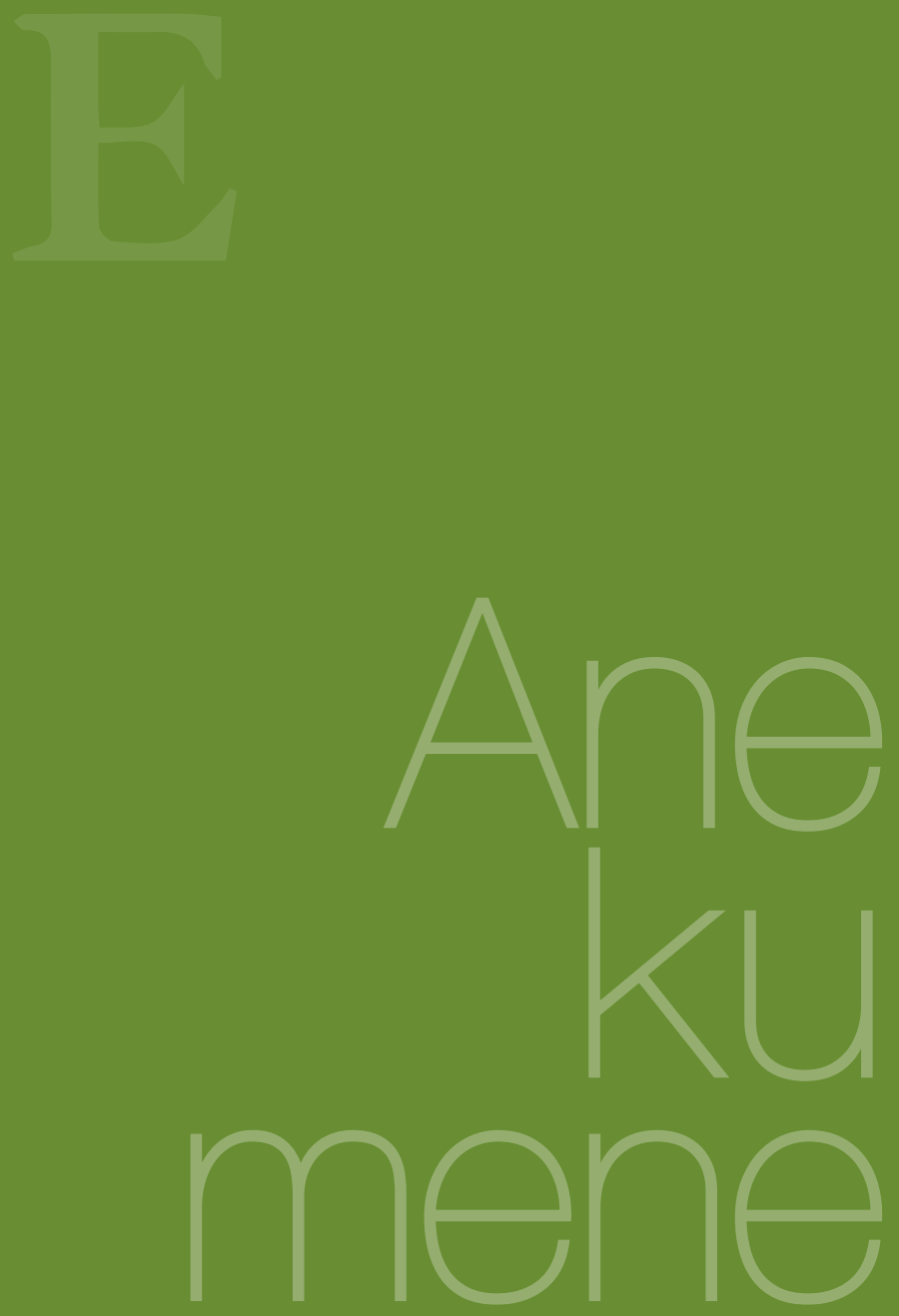


\section{Aproximación a la construcción de la ciudad a partir de los geosímbolos}

\section{Approach to the Construction of City from Geosymbols Aproximação à construção da cidade a partir dos geosímbolos}

Carlos Alberto Zambrano Barrera ${ }^{1}$

\section{Resumen}

En este artículo se aborda la ciudad de Bogotá a partir de la construcción de sus iglesias católicas como un geosímbolo. Para esto, se elabora un marco teórico que parte desde la concepción ontológica del espacio, y se contrasta dicha concepción con otras posturas teóricas sobre la concreción en las formas de apropiación. Finalmente, se hace un recorrido por algunos aspectos que inciden en la transformación de las primeras iglesias católicas en geosímbolos para el turismo cultural en Bogotá.

\section{Palabras clave}

espacio, ciudad, geosímbolo

1 Docente, Universidad EAN. 


\begin{tabular}{|c|c|}
\hline Keywords & Abstract \\
\hline space, city, geosymbol & $\begin{array}{l}\text { In this article Bogotá city is presented based on the construction of } \\
\text { Catholic churches as a key geosymbol in the city. For this purpose, a } \\
\text { theoretical framework that starts from the ontological idea of space is } \\
\text { developed and contrasted with other theoretical positions about forms } \\
\text { of ownership. Finally, a tour on some of the aspects that influence the } \\
\text { transformation of first Catholic churches into geosymbols for cultural } \\
\text { tourism in Bogotá is made. }\end{array}$ \\
\hline
\end{tabular}

\section{Palavras-chave}

espaço, cidade, geosímbolo

\section{Resumo}

Bogotá é abordada a partir da construção do geosímbolo, particularmente desde suas igrejas católicas. Para isso elabora-se um marco teórico partindo da concepção ontológica do espaço, o qual se averigua com outras posturas teóricas sobre a solidificação nas formas de apropriação. Finalmente far-se-á um recorrido por alguns aspectos que afetam na transformação das primeiras igrejas católicas em geosímbolos para o turismo cultural em Bogotá. 


\section{Introducción}

En las propuestas curriculares en torno al turismo es común observar que se dedica gran parte de los contenidos a trabajar sobre aspectos de tipo económico. Se incluyen aspectos como los encadenamientos productivos, la oferta turística, la demanda y los clusters, entre otros. El abordaje de los conceptos y las categorías se hace desde lo que han establecido organismos internacionales como la Organización Mundial del Turismo (WTO, por sus siglas en inglés) o la UNESCO, en lo referente al patrimonio y, en general, al campo cultural.

En este panorama es posible observar un espacio poco abordado, como lo es la relación entre la actividad turística y su relación con la cultura y el patrimonio. Al ser el turismo una actividad que implica el desplazamiento de un lugar a otro por un periodo determinado, se parte de la base de que el turismo es una actividad que depende de la espacialidad.

En este escrito se pretende abordar los elementos teóricos que permiten comprender el proceso de configuración espacial a partir del concepto de geosímbolo, como base para el desarrollo del turismo cultural. Finalmente, se pretende realizar una aproximación al caso de la ciudad de Bogotá, toda vez que se perfila como un destino turístico con un fuerte componente de carácter cultural.

Para cumplir con los objetivos propuestos, se parte de la concreción de un concepto de espacio desde la ontología, para dar paso a la espacialidad. Posteriormente, se hace referencia a la configuración de lo espacial y la construcción del símbolo cultural, que es la base para la actividad turística. Por último, se lleva a cabo un ejercicio de aproximación al caso de la ciudad de Bogotá, para observar su configuración con esta perspectiva.

\section{Del espacio a la espacialidad}

En la vida cotidiana se emplea el término espacio de forma indiscriminada. Los significados se dan por entendido, en la medida en que el contexto aporta la suficiente información para determinar, por parte del oyente, a qué "espacio" se refiere el hablante o que "lugar" está denominando. Ello le confiere a este concepto un carácter polisémico. En consecuencia, con dicho argumento es posible preguntarse acerca de lo que se debe entender por espacio.

Analíticamente, Nicolai Hartmann (1960) presenta tres tipos de espacio: “(...) el espacio intuitivo, que solo existe en la conciencia percipiente, y hay el espacio ideal, del que trata la geometría; pero ninguno de los dos es el espacio real" (p. 53).

El primer tipo de espacio es “(...) asequible a la inmediata intuición interna" (Hartmann, 1960, p. 79), lo que puede equivaler a la capacidad del ser humano para percibir el espacio más inmediato. A su vez, para
Manuel Delgado (2007), eso representa la dualidad dentro/afuera, que "(...) son [en] esencia campos móviles que no tienen por qué corresponderse con escenarios físicos concretos" (p. 32); es decir, son construcciones sociales que en algunos casos se plasman en escenarios físicos como los templos, las ágoras políticas o el simbolismo de un mall, o centro comercial. Un afuera regido por la indeterminación, el afuera es un espacio no construido (llámese parque o calle); un escenario sin reglas estrictas, pero con un deseo desde el poder de control social.

Por otra parte, para Giménez (2000), la clave de este tipo de espacio radica en las formas de apropiación, lo que da origen al "territorio", en la medida en que se comportan "como soportes privilegiados de la actividad simbólica y como lugares de inscripción de las 'excepciones culturales' concluye, el autor, afirmando que un espacio es un 'territorio' cuando el espacio es apropiado y valorizado - simbólica y/o instrumentalmente- por los grupos humanos" (p. 90).

Esta apropiación del espacio intuitivo conlleva establecer un dominio sobre él, lo que implica establecer formas de control. El control no se hace sobre el espacio como tal. Se hace sobre el "sistema de dimensiones de magnitud extensiva" (Hartmann, 1960, p. 78). Es decir, se da paso al segundo tipo de espacio, que es el "espacio geométrico". Dicho espacio tiene la propiedad de tener magnitudes; como tal, es cuantificable. La visión sobre este tipo de espacio tiende a homogeneizarlo y a establecer las categorías de las corporeidades que allí existen (Hartmann, 1960). Eso es lo que constituye lo "espacial" del espacio, si se permite el juego de palabras.

El control se hace "(...) a partir de categorías diáfanas y rígidas a la vez -zonas, vías, cuadrículas”. Que se trazan a partir de lo que Delgado denomina "esa voluntad de amaestrar lo urbano" mediante la creación de un "espacio arquitecturizado". (Delgado, 2007, p. 14)

Para Giménez el control territorial implica tres tipos de operaciones: "creación de mallas, implantar nudos y crear redes" (2000). Para dividir el espacio en diferentes escalas se hace uso de las mallas. En estas los nudos se constituyen como los centros del poder, los cuales son representados por aldeas, pueblos y ciudades. El concepto de red se establece para un mínimo de tres líneas que permiten el relacionamiento de los nudos, como las redes de carreteras, de comunicaciones, entre otras. (Giménez, 2000)

El espacio intuitivo y el espacio geométrico son dos formas del espacio real. Este último, según Hartmann, no tiene "existencia", dado que esta categoría es propia de los seres vivientes (Hartmann, 1960). Entonces, lo que lo hace real es la presencia de "cosas reales" y, lo más importante, "las relaciones entre estas cosas". No es la sola presencia de objetos dimensionales, sino la relación dinámica que se da entre los objetos físicos y la vida humana, la cual transcurre sobre un ambiente natural, de manera individual y colectiva, en un devenir histórico (Hartmann, 1960). O, como afirma Baudrillard (2012), "Sin relación no hay espacio, 
pues el espacio no existe sino abierto, suscitado, ritmado, ampliado por una correlación de los objetos y un rebasamiento de su función en esta nueva estructura" (p. 17).

Esta es una distinción que comparte Delgado (2007), cuando establece la diferencia entre "espacio urbano diseñado" y "espacio urbano real". El primero se corresponde con el espacio geométrico como se explicó más arriba. Mientras, el segundo, el "espacio urbano real", es donde se desarrollan las interacciones sociales entre un innumerable conjunto de actores. Desde los dominios del poder, este escenario siempre ha sido objeto de control, por lo cual se considera que el espacio urbano real debe ser "neutral" y "neutralizado" asignándole una serie de funciones que permitan:

1. Asegurar la buena fluidez de lo que por él circule.

2. Servir como soporte para las proclamaciones de la memoria oficial; $y$

3. Ser objeto de todo tipo de monitorizaciones para el control del orden político,

4. Añadiendo una cuarta función podría decirse que hoy en día convertir a los actores en el espacio como "consumidores del espacio público. (Delgado, 2007, p. 17)

Finalmente, se puede afirmar que el análisis del espacio requiere categorías que permitan vislumbrar las diversas aristas, su concreción y la forma como se articulan dando forma y contenido al espacio real, que es en el que se desenvuelven los individuos. Es donde se produce la reproducción de los procesos de pensamiento espacial, es sobre la espacialidad y sobre el espacio real como las dinámicas económicas y políticas ejercen su mayor influjo.

\section{Ciudad y cultura}

Ciudad y cultura son dos conceptos de un alto grado de complejidad, abordados desde múltiples miradas; en un espacio tan reducido, es imposible abordar todas las teorías y explicaciones que ameritan. Por tal motivo, la atención se centrará en los tres tipos de espacio abordados en la sección anterior. En este sentido, la ciudad tiene tres componentes fundamentales: es un centro de percepciones y de imaginarios; es un escenario de mallas, redes, nodos, divisiones y subdivisiones, líneas, paralelepípedos, $y$, finalmente, es el lugar en el que se desarrolla gran parte de la vida moderna. Como tal, es el resultado de procesos económicos; la ciudad es producto de las relaciones de producción vigentes en cada época de la historia, de su propia historia, es el resultado de la organización del poder, de la forma como se estructuran las políticas públicas, las formas de habitar, las formas de ser de sus habitantes.
El espacio real, aquel donde sucede la vida, es el escenario de la cultura, entendida desde tres aspectos clave. El primero, desde la percepción y la intuición. El segundo, desde la forma de la ciudad que condiciona de cierta manera los comportamientos. Y el tercero, las relaciones que se tejen sobre el espacio y en el espacio. Se parte de la idea de que los sujetos construyen imágenes de diversas formas; estas, a su vez, permiten comprender el entorno y configuran la actuación ante diversas situaciones que se presentan. Todo ello se traduce en la no neutralidad de la imagen. Según Jacques Aumont (1992), hay tres modos como se emplea la imagen: uno simbólico, en la medida en que las imágenes dan acceso a lo que se considera sagrado, en sus orígenes, y luego adquieren nuevas funcionalidades frente a la laicización de la vida; sobre todo, en Occidente. El segundo modo es el epistémico, en el cual la función de la imagen es el aporte de conocimiento. El tercero es el modo estético, en el cual la imagen aporta sensaciones, por lo cual dicha imagen está asociada al arte (p. 84).

Estas funcionalidades de la imagen se refuerzan con la forma que adquiere la ciudad. Así, Kevin Lynch (1985) advierte que “(...) es evidente que los elementos físicos tienen importantes efectos sobre las personas (...)", y aclara que esta situación no es generalizable para todo el conjunto de la población, por lo cual “(...) no es posible construir una teoría transcultural (...)” (p. 80). Por ello, el "homo urbanus” que plantea García Canclini (1999, p. XI) hay que matizarlo y ponerlo en diversas capas que permitan comprender su accionar. Capas económicas, políticas y de la dinámica mundial, todas las cuales actúan como agentes modeladores del paisaje urbano.

Según Castells (citado por Signorelli, 1999, p. 41), las relaciones se dan entre los sujetos en el espacio y entre estos y el espacio. Siguiendo a Lefebvre, este plantea la relación entre tres elementos: "el espacio, la cotidianidad y la reproducción capitalista de las relaciones sociales" (Lefebvre, citado por Lezama, 2005, p. 250). En este contexto, Lefebvre entiende la cotidianidad como "un conjunto de prácticas", resultado de la alienación del sistema productivo y que se desarrollan en la ciudad. (Lezama, 2005, p. 251). Un sistema que ha llevado a mercantilizar el espacio convirtiéndolo en un producto de consumo, cuyos ejemplos serían "el turismo y el comercio del tiempo libre" (Lefebvre, citado por Lezama, 2005, p. 256).

En esta tensión entre la vida cotidiana y el sistema de producción, los sujetos se mueven en dinámicas que permiten la resignificación de los espacios para transformarlos en códigos elaborados. Esto se logra mediante la apropiación y valoración de los lugares. Puede obedecer a una necesidad como la de movilizarse, de estudiar o de trabajar, lo que le imprime un carácter funcional-instrumental. La otra lógica se corresponde con el deseo, el cual, a su vez, requiere expresión tanto del objeto como del sujeto en el espacio y con el espacio. Como afirma Giménez (2000), el espacio es "objeto de inversiones estético-afectivas" (p. 93). 


\section{Espacio geosimbólico}

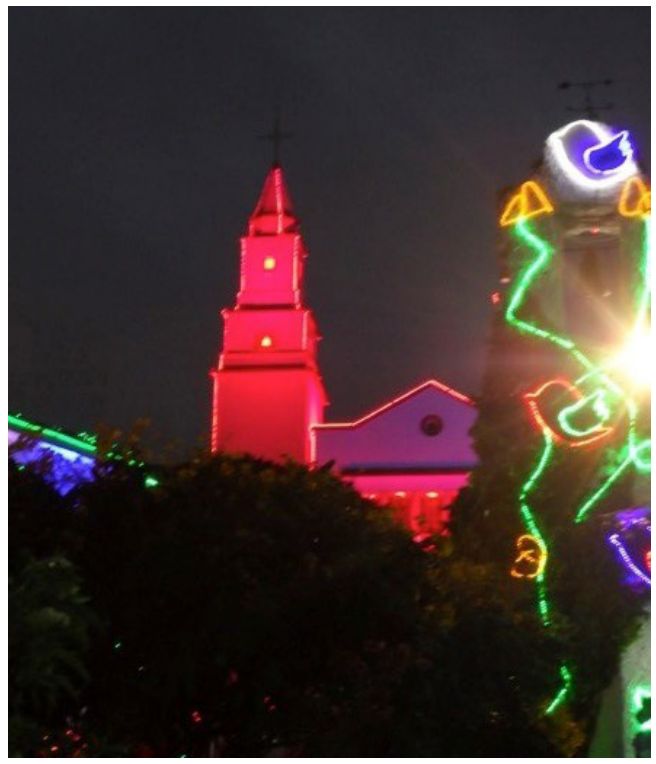

Figura 1. MONSERRATE 1

Estas inversiones van asociadas a la percepción del espacio como "(...) paisaje, como objeto de apego afectivo, como lugar de inscripción de un pasado histórico y de una memoria colectiva y, en fin, como geosímbolo" (Giménez, 2000, p. 93). Así, el espacio es entendido como "un lugar, un itinerario, una extensión o un accidente geográfico que por razones políticas, religiosas o culturales revisten a los ojos de ciertos pueblos o grupos sociales una dimensión simbólica que alimenta y conforta su identidad" (Bonnemaison, citado por Giménez, 2000, p. 101).

El geosímbolo es una construcción cultural que se hace sobre un objeto, un grupo o un proceso, sobre los cuales se crea una representación como símbolo de la pertenencia territorial de ese grupo sobre el objeto, el cual, a su vez, es integrado al sistema cultural y se expresa mediante el lenguaje. Tiene un carácter subjetivo, y, como tal, no obedece a las formas geométricas del espacio ni a las divisiones políticas-administrativas del espacio, así este último pretenda normativizarlo. Por ello, se puede hablar de "el espacio cultural”, que es un "espacio geosimbólico" (Giménez, 2007, p. 17). En palabras de Bonnemaison, en este se da una "(...) comunión con un conjunto de signos y valores” (citado por Giménez, 2007, p. 17).

Una comunión que forja procesos identitarios con el espacio, en la medida en que este se transforma en un "lugar venerado", en "lugar santo" o en "lugar sagrado", (Bonnemaison citado por Giménez, 2007, p. 17). Tal idea conduce a explorar de forma breve la manera como estos lugares cambian de ser funcionales a transformarse en simbólicos, y de allí, a adquirir nuevas funcionalidades.
Para abordar esta transformación de funcional a simbólico, se parte de un fenómeno que ha venido adquiriendo relevancia a lo largo de los últimos años, y es la patrimonialización de la cultura. La construcción del patrimonio cultural se ha vinculado con la producción y la circulación de los bienes culturales, como producto de lo cual se escinde el valor del objeto entre el consumo y su valor simbólico (Guerrero, 2005). Esto, en la medida en que la patrimonialización se da a partir de las políticas públicas y obedece a unos criterios particulares, los cuales no siempre van en concordancia con los procesos que se dan en el contexto social y cultural de la población. Por esto, Rosa Guerrero hace la distinción entre "el patrimonio efectivamente vivido (...) y lo que algunos llaman ideología patrimonial, cuyos propósitos son a veces de orden pre formativo o político" (2005). Este distanciamiento repercute en que no se construya un auténtico geosímbolo cultural.

\section{Geosímbolos y Bogotá}

Para abordar la categoría de geosímbolo, se retoman los tres aspectos mencionados en la definición dada por Bonnemaison: el político, el cultural y el sagrado. Centramos la atención en este último aspecto. Ello nos arroja la existencia de dos tipos de espacio: el profano y el sagrado. Así es como, de acuerdo con las cifras del portal de la Secretaría de Cultura, Recreación y Deporte ${ }^{2}$, Bogotá cuenta con 1544 lugares de culto.

¿Cómo entender estos espacios considerados sagrados? Silvia Santarelli y Marta Campos (2011), proponen tomarlos como "un campo de fuerzas de valores que eleva al hombre religioso por encima de sí mismo" (p. 3). Es el espacio donde el hombre entra en contacto directo con una entidad trascendente.

En este espacio se producen unas prácticas normativizadas, pero internalizadas hasta naturalizarse; basta con ver cuando los católicos pasan cerca de un templo haciéndose la señal de la cruz sobre sus frentes y sus pechos, lo que retroalimenta el simbolismo de ser un espacio sagrado.

Si bien es cierto que existen numerosos lugares de culto, no todos son geosímbolos; también cabe tomar en cuenta que de la cifra mostrada, no todos son católicos. En las páginas amarillas se encuentra un registro de 423 lugares católicos que incluyen capillas, parroquias e iglesias, entre otros. De estos, solo algunos alcanzan a tener las características para ser catalogados como geosímbolos dentro de la ciudad. El referente es el centro histórico de la ciudad, el cual, acorde con la división del espacio geométrico, se corresponde con la Localidad de La Candelaria, que alberga las construcciones eclesiásticas de mayor antigüedad de Bogotá.

El componente histórico es uno de los elementos clave a la hora de abordar la construcción geosimbólica del lugar. La instauración de las iglesias católicas se realiza desde el mismo momento en que Colón llega a

2 http://www.culturarecreacionydeporte.gov.co/bogotanitos/bogodatos/ bogota-ciudad-de-iglesias 
América, y, a medida que avanza la exploración del territorio y su conquista, la corona española establece dos frentes. Por un lado, el dominio físico de las nuevas tierras, y por el otro, el dominio espiritual de sus pobladores. Ello requería el dominio de la lengua, y para tal fin se plantearon tres estrategias: una, llevar a indígenas a España para que aprendieran la lengua y sirvieran como posteriores traductores; la segunda, enviar a españoles a convivir con las comunidades indígenas que los acogieran, para que aprendieran las lenguas nativas, y la tercera, y más efectiva, iniciar la evangelización con los niños (Téllez, 1992).

La construcción de lugares donde realizar la evangelización se convirtió en prioridad tanto para los nuevos "fieles" como para los peninsulares que habitaban estas tierras. Así se buscaba que "(...) los nativos fueran intuyendo la existencia de un Ser Superior", por lo cual los templos debían reflejar que este Ser era "(...) digno de casas bellas y grandes, digno de plegarias y respeto" (Téllez, 1992, p. 114). La primera iglesia en Bogotá se construye a petición de Fray Domingo de las Casas, quien “(...) les advirtió [a Quesada y los otros conquistadores] que se debía hacer una casa que sirviera de iglesia, para estrenar la fundación con el Santo Sacrificio de la Misa" (Zamora, citado por Téllez, 1992, p. 123). Los misioneros van llevando la evangelización a cada uno de los poblados indígenas; en algunos de ellos, el templo católico se superpone al templo indígena, tal como se narra en este fragmento de las crónicas de Fray Alonso de Zamora:

El padre Fray Juan Méndez purificó el templo del sol con las bendiciones eclesiásticas y levantando en él la Cruz fue el primero que hubo en aquella corte, cabeza del reino de Bacatá y como en éste, así en muchos otros pueblos de la sabana; derribaba los ídolos y echándolos fuera, colocaba en su lugar la Cruz y celebraba el Santo Sacrificio de la Misa. (Téllez, 1992, p. 124)

Estas primeras construcciones fueron demolidas en varias oportunidades y volvieron a levantarse, con materiales cada vez de mayor resistencia tanto a los efectos del clima como a los sismos que sacudían la ciudad.

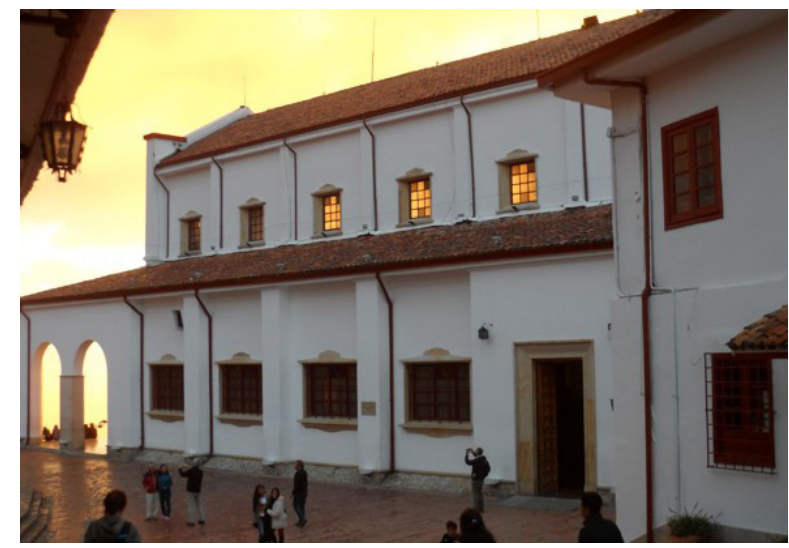

Figura 2. IGLESIA DE MONSERRATE 2
Acorde con este contexto, las primeras construcciones hispánicas destinadas a rituales católicos cumplen diversas funciones: por un lado, mostrar el poder de Dios; por otro, servir de centro de evangelización, y aún más, mantener la fe entre los propios españoles. Es un espacio funcional. Luego pasa a ser un espacio funcional-geométrico, en la medida en que la ciudad se organiza alrededor de las parroquias existentes. Para 1185 aparece el Nuevo Plano de Bogotá, con las siete divisiones de la ciudad en las siguientes parroquias: por una parte, la Catedral, Las Nieves, Santa Bárbara y San Victorino, que eran las más antiguas. Las nuevas parroquias eran: Las Aguas, Las Cruces y Egipto. Incluso en el lenguaje, algunas personas mayores aún emplean el término parroquiano para referirse a alguna persona en particular. De la funcionalidad original se da paso a una funcionalidad político-administrativa, los templos se vuelven referentes del espacio geométrico.

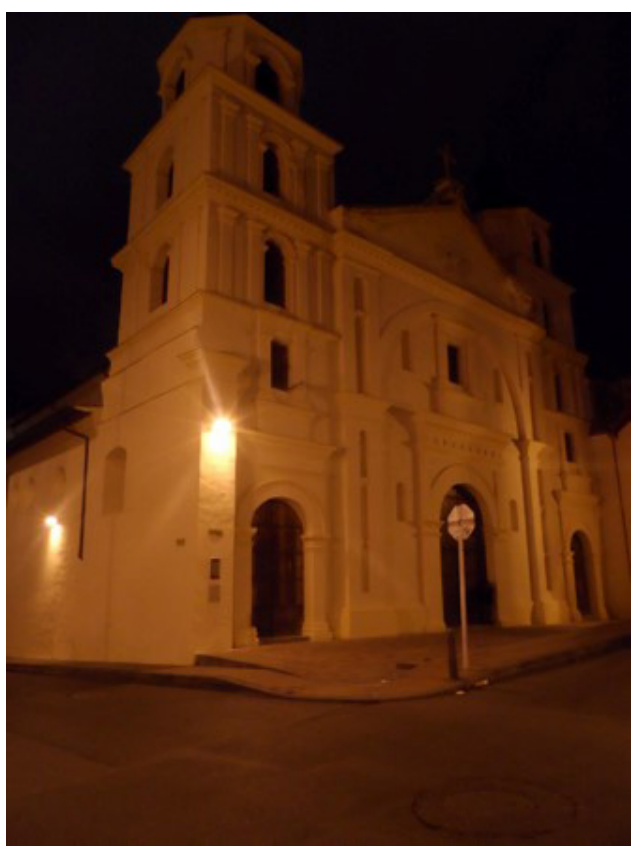

Figura 3. IGLESIA DE LA CANDELARIA

La expansión de la ciudad, aunada al abandono del centro histórico, coadyuva al proceso de gentrificación del lugar. El centro adquiere la connotación de ser peligroso; sin embargo, las iglesias no dejan de ser visitadas por todo tipo de turistas. Se crea el plan de renovación del centro histórico, el cual ha levantado bastantes polémicas. Pero este plan busca resignificar este espacio $^{3}$. Esta labor implica, por un lado, el trabajo sobre el patrimonio: la recuperación de los antiguos cafés (programas como Bogotá en un Café, - Tomate el centro ${ }^{4}$ ), la restauración y el mantenimiento de los bienes de interés cultural como las iglesias y la creación de rutas turísticas. Es decir, el ingreso del centro de la ciudad en los bienes de consumo cultural.

\footnotetext{
3 Para mayor información se puede consultar: http://www.ub.edu/geocrit/ coloquio $2014 /$ Jennifer $\% 20$ Cruz $\% 20$ Hernandez.pdf

4 Ver el programa en: http://idpc.gov.co/bogota-en-un-cafe/
} 
Como se evidencia en la figura 4 , se establecen recorridos ${ }^{5}$, unos permanentes y otros por temporadas, para todo tipo de públicos. Incluso, algunos de dichos recorridos se ofrecen en inglés. El caso del mapa de la figura 4 muestra parte de la localidad, describe de forma breve los recorridos y los resalta en el mapa. Este, a su vez, tiene como referentes las iglesias: la Catedral Primada, en la plaza de Bolívar; el museo Iglesia de Santa Clara; la Iglesia de La Tercera; la Iglesia de Las Nieves; la Iglesia de La Candelaria; la Iglesia de Las Aguas; la iglesia del Cerro de Monserrate; y aunque no se nombra allí, también aparece la Iglesia de San Francisco.

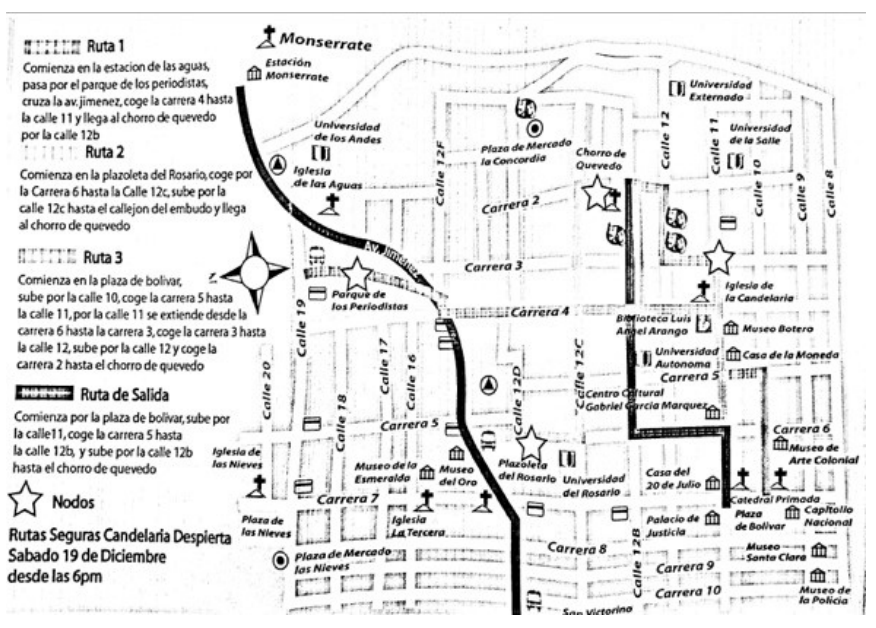

Figura 4. MAPA RECORRIDOS CENTRO HISTÓRICO DICIEMBRE 2015

\section{A manera de conclusión}

El espacio tiene diversas caras. Se destacan tres de ellas: el espacio intuitivo, el geométrico y el espacio real. La relación entre los tres permite comprender las dinámicas que se tejen en el espacio y con el espacio. El espacio real es donde sucede la vida y donde los sujetos establecen las dinámicas que configuran lo espacial.

Estas dinámicas obedecen, a su vez, a tres elementos: la vida cotidiana, el espacio y el sistema de producción (que para este caso es el capitalismo). Este último, a su vez, ha visto en el tiempo libre un escenario de incursión con los bienes de consumo cultural, por lo que las prácticas culturales plasmadas en acciones como ir a cine, ver televisión, leer un libro o ir a festivales, entre otros, hacen parte de tal tipo de consumo. No es gratuito que a la producción de libros, revistas, festivales y otros se las denomine industrias culturales y del entretenimiento.

5 Este plano se ofreció a los transeúntes en el marco de la plaza de Bolívar en los primeros días del mes de diciembre de 2015.

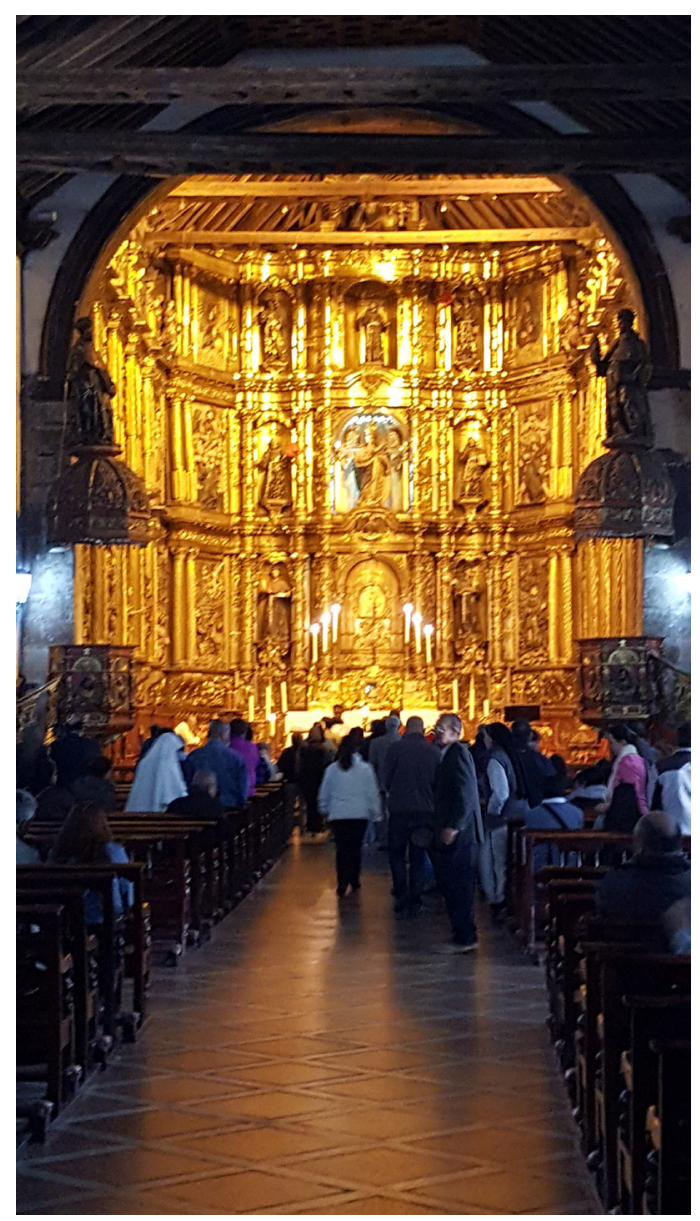

Figura 5. IGLESIA DE SAN FRANCISCO

El turismo, como parte de este tipo de actividades, adquiere un valor económico importante. Bogotá se ha venido destacando a escala nacional en el turismo ejecutivo, de negocios, pero ha ido incursionando también en el turismo de tipo cultural, tomando como base la riqueza patrimonial.

Por lo anterior, el geosímbolo ha venido adquiriendo una importancia relativa; sobre todo, por el desconocimiento que tienen los mismos habitantes de la ciudad respecto a los atractivos culturales de esta, o porque no se tiene conciencia de que es parte de la riqueza cultural. La construcción del geosímbolo implica un largo proceso de transformaciones de la funcionalidad del objeto; es decir, de su relación con las comunidades. Este modelo de análisis que se propone se llevará a la práctica en diversos escenarios universitarios, para evaluar su aplicabilidad y los resultados a los que se puedan llegar con los estudiantes. 


\section{Referencias}

Aumont, J. (1992). La imagen. Barcelona: Paidós.

Baudrillard, J. (2012). El sistema de los objetos. Bogotá: Siglo XXI.

García-Canclini, N. (1999). En A. Signorelli. Antropología urbana (pp. 9-16). México: Anthropos.

Delgado, M. (2007). Sociedades movedizas. Barcelona: Anagrama.

Giménez, G. (2000). Territorio, Cultura e identidades. La región sociocultural. Recuperado de http://www.culturascontemporaneas.com/ contenidos/region_socio_cultural.pdf

Giménez, G., Héau Lambert, C. (2007). El desierto como territorio, paisaje y referente de identidad. Culturales [en línea], enero-junio. Recuperado el 30 de diciembre de 2015 de: http://www.redalyc. org/articulo.oa?id=69430502.

Gómez, J., Muñoz, J. y Ortega, N. (1982). El pensamiento geográfico. España: Alianza Universidad.

Guerrero, R. (2005). Identidades territoriales y Patrimonio Cultural: La apropiación del patrimonio mundial en los espacios urbanos locales.Revista F@ro (1),2. Recuperado el 30 de diciembre de 2015 de: http://web.upla.cl/revistafaro/n2/02 guerrero.htm
Hartmann, N. (1960). Ontología IV, Filosofía de la Naturaleza, Teoría especial de las categorías. Buenos Aires: Fondo de Cultura Económica.

Lezama, J. (2005). Teoría Social, espacio y sociedad. El Colegio de México, Centro de Estudios Demográficos y de Desarrollo Urbano. México D.F.

Lynch, K. (1981/1985). La buena forma de la ciudad. Barcelona: Gustavo Gili.

Santarelli, S. y Campos, M. (2011). Geografía de las religiones, espacios locales y subjetividad. Una nueva mirada en la enseñanza universitaria. Revista Geográfica de América Central, Número Especial EGAL, 2011. Recuperado el 19 de noviembre de 2015 de: http:// www.revistas.una.ac.cr/index.php/geografica/article/view/2599

Téllez, L. (1992). Iberoamérica y sus inicios cristiano culturales. Padres Dominicos. 